\title{
Water in minerals from ultrahigh- pressure metamorphic rocks: implications for fluid activity in continental subduction zone
}

\author{
REN-Xu CHEN*, BING GONG, Yong-FeI ZHENG
}

CAS Key Laboratory of Crust-Mantle Materials and

Environments, School of Earth and Space Sciences,

University of Science and Technology of China, Hefei

230026,China chenrx@ustc.edu.cn

Hydrous minerals and nominally anhydrous minerals (NAMs) together constitue water reservior of sudbuction zone. Determining their water contents and affecting factors is critical for understanding fluid activity in the subduction zone. Water contents and hydrogen isotopes of minerals can be stimultaneously obtained by the thermal conversion elemental analyzer and gas isotope mass spectrometry (TC/EA-MS). Water contents and $\mathrm{H}$ isotopes of both structural $\mathrm{OH}$ and molecular water in NAMs can be both determined by a new continuous flow method combining high vacuum step heating (HVST) device with TC/EA-MS. Combining a newly developed vacuum-He purge autosampler, the interference of adsorption water can be minimized. Molecular water has higher mobility and lower $\delta \mathrm{D}$ value than structural $\mathrm{OH}$. The stability of hydrous minerals and water capacity of NAMs control the fluid availability in the subduction zone. Water would be redistributed between different minerals, rocks and slabs deepenging on the water capacity of different phases. The stability of hydrous minerals was controled by the thermal structure of the subduction zone. Water contents of NAMs in the UHP rocks were controlled by several factors such as protolith nature, temperature, pressure and composition. Decompression exsolution of water during exhumation likely plays a key role. NAMs not only transport water to deep mantle during subduction but also release significant amount of fluid during exhumation in the continental sudbuction zone. Different types of water in NAMs would exchange with each other during subduction zone processes, and molecular water is more readily released during dehydration. The continental subduction zone likely has similar fluid activity at subarc to posrarc depths as the oceanic subduction zone. The water released from hydrous minerals and NAMs would form aqueous fluid, hydrous melt and even supercritical fluid at different times and positions in the continental subduction zone, mainly depending on the themal structure of subduction zone and nature of the slabs. The produced fluid would flow between different units, resulting in mass transfer in the interior of the slabs and crust-mantle interactions in continental subduction zone. 